\title{
NAM 2017 Report: A National Plan to Eliminate Hepatitis B and C in the United States by 2030 and the AASLD's Response
}

$\mathrm{T}$ he public health significance of viral hepatitis (VH) cannot be overstated: $\mathrm{VH}$ kills more people worldwide each year than human immunodeficiency virus (HIV), traffic accidents, and diabetes. ${ }^{(1)} \mathrm{VH}$ accounts for $\sim 1.5$ million deaths globally, of which chronic hepatitis $\mathrm{B}$ and $\mathrm{C}$ virus (HBV, $\mathrm{HCV}$ ) infections account for $96 \%$. The high mortality is mainly attributed to complications of cirrhosis and hepatocellular carcinoma (HCC), making chronic $\mathrm{VH}$ the seventh leading cause of deaths worldwide. Given these grim statistics, in 2016 the World Health Organization (WHO) drafted a VH strategy, the goal of which was elimination of $\mathrm{VH}$ as a major public health threat by 2030. More specifically, the goals were to reduce the incidence of chronic hepatitis B and C infections by $90 \%$ by 2030 and to reduce mortality attributed to these chronic infections by 65\%. The WHO's 2016 strategy document identified five areas in which action will be needed, referred to as strategic directions. These five strategic directions were meant to serve as a guide to help countries formulate their national strategies. Consequently, in 2016 the

Abbreviations: AASLD, American Association for the Study of Liver Diseases; CDC, Centers for Disease Control and Prevention; $D A A s$, direct-acting antivirals; $H B s A g$, hepatitis $B$ surface antigen; $H B V$, hepatitis $B$ virus; $H C C$, hepatocellular carcinoma; $H C V$, hepatitis $C$ virus; HHS, Department of Health and Human Services; $H I V$, buman immunodeficiency virus; NASEM, National Academies of Sciences, Engineering and Medicine; VH, viral hepatitis; WHO, World Health Organization.

Received July 6, 2017; accepted July 6, 2017.

Copyright (c) 2017 by the American Association for the Study of Liver Diseases.

View this article online at wileyonlinelibrary.com. DOI 10.1002/hep.29361

Potential conflict of interest: Dr. Chung received grants from Gilead, AbbVie, Janssen, and Merck. Dr. Lok received grants from Bristol-Myers Squibb and Gilead.
National Academies of Sciences, Engineering and Medicine (NASEM) convened a VH task force to address the question of whether it was feasible to eliminate hepatitis B and C from the United States. The committee concluded that elimination of hepatitis $\mathrm{B}$ and $\mathrm{C}$ was a realistic goal, but substantial barriers would need to be overcome. In 2017, the NASEM drafted a national strategy patterned on the WHO plan, which presents a roadmap to achieve this goal. This would be predicted to avert approximately 90,000 deaths by 2030. To achieve these goals, five specific areas were outlined in the report: information (e.g., disease burden); interventions (what specifically will need to be done); service delivery (i.e., necessary infrastructure and implementation); financing; and research (identify major gaps in knowledge and approaches to enhance the elimination effort).

\section{Hepatitis B}

It is estimated that there are 850,000 to 2.2 million persons with chronic $\mathrm{HBV}$ infection in the United States. If the United States were to meet the WHO target of diagnosing $90 \%$ of cases of chronic hepatitis $\mathrm{B}$, linking $90 \%$ of those to care, and treating $80 \%$ eligible patients, this would result in a $50 \%$ reduction in mortality from chronic hepatitis B and avert 60,000 deaths in the United States by 2030. The same level of diagnosis, care, and treatment would be expected to reduce the incidence of $\mathrm{HBV}$-related $\mathrm{HCC}$ by around $33 \%$ and incidence of $\mathrm{HBV}$-related cirrhosis by around $45 \%$. To achieve these goals will require partnership with the highest levels of the federal government as well as nonfederal stakeholders (state and local health departments). The best way to prevent new HBV infections is by interrupting transmission through effective use of the HBV vaccine. Preventing motherto-child transmission of $\mathrm{HBV}$ is most important. 
Therefore, all infants born to hepatitis B surface antigen ( $\mathrm{HBsAg}$ )-positive mothers should receive hepatitis $\mathrm{B}$ immune globulin and $\mathrm{HBV}$ vaccine and all $\mathrm{HBsAg}^{+}$ pregnant women should be tested for HBV DNA and liver chemistries to evaluate whether antiviral prophylaxis is necessary. In addition, states should expand access to adult hepatitis $B$ vaccination such as removing barriers to free immunization in pharmacies and other easily-accessible settings. Undiagnosed cases of chronic hepatitis B will need to be identified through improved screening. In this regard, federal and nonfederal agencies should identify settings appropriate for enhanced $\mathrm{VH}$ testing based on known prevalence. Along with this, the National Committee for Quality Assurance should establish measures to monitor compliance with VH screening guidelines and hepatitis B vaccine birth dose coverage and include the new measures in the Healthcare Effectiveness Data and Information Set. Many people suffering from hepatitis B are not in contact with the health system, so the elimination strategy must allocate sufficient attention and resources to the delivery of services, including building infrastructure to allow for an increase in treatment capacity. The federal government should work with states to build a comprehensive system of care and support for special populations with hepatitis B similar to the Ryan White system. The prison population bears a particularly high burden of hepatitis B, and the criminal justice system should screen, vaccinate, and treat hepatitis $\mathrm{B}$ and $\mathrm{C}$ in correctional facilities per national clinical practice guidelines. These goals will not be achievable without the appropriate financing and continued collection of data on the effectiveness of the strategy and gaps in knowledge.

\section{Hepatitis C}

Direct-acting antivirals (DAAs) to treat all chronic $\mathrm{HCV}$ patients without restrictions on severity of disease or social status and a consistent ability to diagnose new cases, even as prevalence of $\mathrm{HCV}$ decreases, are required to meet the goals outlined in this important document. Considering that people who inject drugs account for around $75 \%$ of new HCV infections, states and federal agencies need to expand access to syringe exchange and opioid agonist therapy. One of the primary bottlenecks for hepatitis care is the need for patients to be treated by specialists; essentially, this means that many patients in rural and underserved areas do not have access to curative therapies. The
NASEM report encouraged the American Association for the Study of Liver Diseases (AASLD) and Infectious Diseases Society of America to partner with primary care providers to manage $\mathrm{VH}$, expanding on collaborative training models with referral for more medically complex patients. Moreover, the report further stipulates that the Department of Health and Human Services (HHS) should work with states to build a comprehensive system of support and care based on the Ryan White Act that was passed to reach marginalized patients with HIV. The criminal justice system will need to screen, vaccinate, and treat hepatitis $\mathrm{B}$ and $\mathrm{C}$ in correctional facilities per national clinical practice guidelines. In order to implement changes to bring about elimination of $\mathrm{HCV}$, it is recommended that the federal government, on behalf of the HHS, should purchase the rights to DAAs for use in neglected segments through licensing or assigning of a patent with an innovator pharmaceutical company. Importantly, the report also recognized the importance of research into novel areas, such as curative therapy for $\mathrm{HBV}, \mathrm{HCV}$ vaccine development, and social studies to characterize high-risk populations (networks of drug users) and alleviate societal stigma.

\section{AASLD Response}

The AASLD, a sponsor of the NASEM deliberation, is delighted that the NASEM task force determined that elimination of hepatitis B and C by 2030 in the United States is feasible and agrees with its recommendations on how to meet this goal. In particular, the AASLD agrees that all stakeholders, including the highest level of federal government, must make elimination of hepatitis $\mathrm{B}$ and $\mathrm{C}$ a priority. The AASLD will collaborate with federal and state government agencies, industry, academia, and the local community to facilitate the implementation of the NASEM recommendations.

AASLD representatives attended a meeting at the Centers for Disease Control and Prevention (CDC) on April 27-28, 2017, in which stakeholders across the country and the NASEM task force reviewed the recommendations and considered implementation strategies. On June 15, 2017, we attended a congressional briefing to urge our government to support the implementation of the NASEM recommendations.

As a professional society, the AASLD's key roles in the implementation of the NASEM recommendations include: (1) advocacy, (2) education, (3) capacity 
building, and (4) research. The AASLD will work with the $\mathrm{CDC}$ and patient societies to raise public awareness about hepatitis $\mathrm{B}$ and $\mathrm{C}$ to increase screening and adoption of preventive measures. The AASLD will continue to advocate for support from federal and state governments to (1) provide the services needed to expand screening, linkage to care, vaccination, and harm reduction, (2) improve the current surveillance system to provide more accurate data on burden of disease and changes in incidence and to allow better exchange of data across state lines, (3) provide funding for research on a cure for hepatitis $B$ and a vaccine for hepatitis $\mathrm{C}$ as well as research on implementation of care, and (4) facilitate access to affordable hepatitis B and $\mathrm{C}$ treatment.

The AASLD has a broad portfolio of educational materials on hepatitis B and C. Some of these materials, such as Fundamentals of Liver Diseases, were specifically prepared for primary care providers and are available online free of charge. We will introduce these valuable resources together with our guidelines to nonhepatologist providers. Our HCV Guidance is webbased and updated regularly to keep pace with the rapid evolution of $\mathrm{HCV}$ treatment and provides treatment recommendations for all groups of patients. The AASLD's $2015 \mathrm{HBV}$ guidelines highlighted the importance of testing $\mathrm{HBsAg}^{+}$mothers for $\mathrm{HBV}$ DNA and antiviral prophylaxis to those with high viremia.

Recognizing that there are not enough hepatologists to treat all patients and that many patients with hepatitis $\mathrm{B}$ and $\mathrm{C}$ are not in close proximity to liver centers, the AASLD plans to continue to expand efforts to train primary care providers to manage these patients. In parallel, we will continue to increase funding to support training of hepatologists and hepatology providers to expand the force of care providers delivering $\mathrm{VH}$ care.

Research has always been a core mission of the AASLD, and we will continue to advocate for increased federal funding for research in developing curative strategies for $\mathrm{HBV}$, broadly reactive and immunogenic $\mathrm{HCV}$ vaccines, and implementation of highly penetrant delivery of $\mathrm{HCV}$ and $\mathrm{HBV}$ care. These areas will be critical for finishing the job of elimination of viral hepatitis.

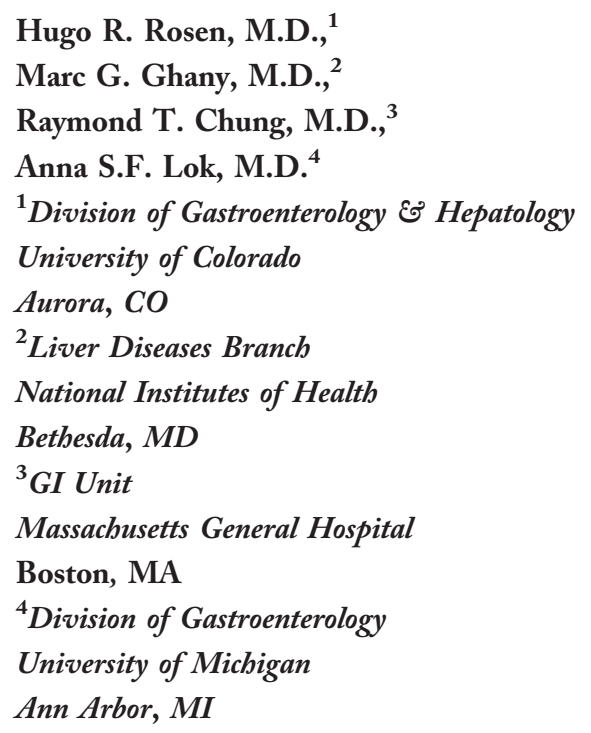

\section{REFERENCE}

1) http://www.nationalacademies.org/hmd/reports/2017/national-strategyfor-the-elimination-of-hepatitis-b-and-c.aspx. Accessed August 11, 2017. 